\title{
LA SELECCIÓN Colombia, El GOBIERNo SANTOS Y LA GUERRILla: LOS DISCURSOS DE LA UNIDAD
}

\section{COLOMBIAN SOCCER TEAM, SANTOS’ADMINISTRATION, AND THE GUERILLAS: UNITY DISCOURSES}

\author{
Alejandro Villanueva Bustos ${ }^{1}$ \\ Universidad Pedagógica Nacional \\ Nelson Rodríguez-Melendro ${ }^{2}$ \\ Universidad Nacional de Colombia
}

\section{Resumen}

Los discursos de la identidad nacional a partir de la Selección Nacional de Colombia (SNC) han sido el tema de varias investigaciones. En especial, la academia se ha centrado en los medios de comunicación masiva y en el de los hinchas para entender las estrategias de esta clase de manifestaciones. En este estudio se analizan cuatro discursos presidenciales, emitidos durante la presentación de la SNC en la Copa Mundo Brasil-2014. El estudio muestra que, para apoyar los Diálogos de Paz, y por esta vía, su reelección, Juan Manuel Santos empleó varios imaginarios populares, como la unidad, la identidad y la fortaleza, excusado en las victorias del combinado nacional. De acuerdo con el presidente, la SNC representaba el sentido de nacionalidad.

Palabras clave: nacionalidad, identidad, unidad, discursos presidenciales.

\section{Abstract}

Discourses of national identity based on the Colombian Soccer Team (CST) had been topic of various studies. Principally, academia had studied fans and media for understand the strategies for conform these classes of discourses. Four Colombian President' speeches are analyzed in this article. The study shows that, for supporting the "Diálogos de Paz" (peace agreement), and, in this way, supporting his reelection, Juan Manuel Santos using some imaginaries around of CST, like unity, identity, strongly, etc., specially based on their victories in World Soccer Cup Brazil-2014; then, according to the President, CST represent the sense of nationality.

Key words: nationality, identity, unity, colombian president' speeches.

Recibido: 05 de septiembre de 2015 Aceptado: 10 de octubre de 2015

En el año 1998, Colombia estaba pasando por una de las etapas de exacerbación de una guerra interna de más de cincuenta años; una violencia generalizada, la cual, tiempo después por su sevicia tristemente sería célebre en el ámbito internacional por los descuartizamientos de campesinos inocentes, y la barbarie generalizada en el campo, lo que se sumaba al proyecto de refundación de la nación por parte de la ultraderecha, unida en un cuerpo armado denominado eufemísticamente las Autodefensas Unidas

1 Licenciado en Ciencias Sociales, Especialista en Pedagogía; Magister en Educación, Doctorante en Ciencias del Deporte por la Universidad Baja California- México. Profesor de la Licenciatura en Deporte, Universidad Pedagógica Nacional y tutor de Ciencias Sociales de la Universidad Nacional Abierta y a Distancia.

2 Lingüista y magister en Sociología por la Universidad Nacional de Colombia. Corrector de estilo y docente. 
de Colombia, quienes se encontraban asociados con los narcotraficantes, la clase dirigente y buena parte del aparato militar oficial (las Fuerzas Armadas de Colombia).

En este contexto, hablar de un acercamiento o algún tipo de diálogo entre las Fuerzas Militares, al servicio de un Estado dominado por la derecha por más de cien ańos, y la insurgencia armada de la década de los sesenta (que había tenido algunos asomos a principios de los años cuarenta y finales de los cincuenta), la cual se organizaría, eso sí muy a la colombiana, en diferentes guerrillas al buscar solucionar el conflicto agrario, la injusticia social y la exclusión política, inspirada en sucesos como la revolución Cubana y el bloque Soviético, era inconcebible: estos dos grupos no podían estar solos en un mismo espacio, lugar o tiempo.

Sin embargo, hacia la década de los setenta y ochenta el movimiento guerrillero M-19 firmaría la paz con el gobierno del presidente Virgilio Barco Vargas el 8 de marzo de 1990; guerrilla que iniciaría su participación en la creación de una nueva constitución política para Colombia y que, posteriormente, entraría al juego democrático de la nación. Otra guerrilla con un talante similar, ya también desmovilizada, el Ejército Popular de Liberación (Epl) había albergado en su seno a un revolucionario entrenado en la china comunista de Mao, llamado Sergio Cabrera, quien cambiaría el fusil por las cámaras de cine, los libretos y la dirección de series o documentales, entre los que se destacan La estrategia del caracol (1993) y Golpe de Estadio (1998).

Es esta última película, desde la ficción, se planteó sentar a la mesa tanto a combatientes de la guerrilla, como a soldados y policías, para juntos deleitar un partido de Selección Colombia en plena selva en septiembre de 1993, donde un débil seleccionado tricolor le ganaría cinco goles a cero a la poderosa y dos veces campeona del mundo: la selección Argentina y, como si fuera poco, con un frustrado Diego Armando Maradona aplaudiendo el buen juego cafetero en medio de su frustración.

Era un interesante anhelo que invitaba la esperanza a la mesa, reflejado en la sentencia del director técnico colombiano Francisco Maturana: "Se vive, como se juega", pero este deseo de unidad mediante la ficción estaría tristemente alejado de una realidad que incluso sobrepasaría el realismo mágico garciamarquiano, pues tiempo después, desde 1998 hasta 2013, en los campos y ciudades de Colombia se viviría una confrontación sin antecedentes en la historia reciente de Latinoamérica: intereses económicos, políticos y territoriales, protegidos e impulsados por la nefasta alianza entre militares, narcotraficantes, funcionarios públicos corruptos, paramilitares, policías, congresistas y élites locales, provocaron, según cifras de Naciones Unidas, un desplazamiento forzado de más de seis millones de campesinos, a quienes despojarían de sus tierras y sustento; junto con esto se fortalecería el fuerte embate neoliberal iniciado a principios de los noventa, lo que adelgazaría al Estado en su componente social, subsidiario y promotor, para fortalecerlo en su parte policial, represiva y de administración de justicia, pero en favor de los poderosos. Por su parte, en estos tres quinquenios se presentó la seguidilla de fracasos deportivos y futbolísticos en torneos como la Copa Libertadores y las eliminatorias a los mundiales de Corea-Japón 2002, Alemania 2006 y Suráfrica 2010, lo que ayudó a exacerbar ese imaginario de pesimismo con respecto a la representación de la idea de Nación y lo nacional, en especial en clave de fútbol.

Hacia el año 2012, y después de una fuerte confrontación entre distintos actores durante más de una década, el gobierno del presidente Juan Manuel Santos Calderón y la plana mayor del secretariado de las FARC deciden iniciar un proceso de negociación con el objetivo de llegar a un proceso de paz duradero para todos los colombianos, aceptando los buenos oficios de Cuba, Noruega, Venezuela y Chile como garantes de estos diálogos; es decir, por primera vez en casi dos décadas, y evocando la ficción recreada por Sergio Cabrera en 1998, representantes de una bando y del otro se pudieron sentar a discutir sus posiciones para en un mediano plazo poder llegar a la tan anhelada paz; es importante destacar que inmediatamente bajó la intensidad del conflicto, hasta llegar a un cese unilateral del fuego por parte de la subversión (con algunos "hechos aislados"). 
No obstante, el primer periodo de gobierno de Santos Calderón, 2010-2014, estaba terminando y el proceso de paz llevaba un ritmo lento pero seguro, por lo que se tenía que dar paso a otra campańa electoral por la presidencia, en la cual se perfilaron dos fuertes contendores: por un lado, el candidato Óscar Iván Zuluaga, representante de la ultraderecha, específicamente del uribismo; y por el otro, el candidato-presidente se presentaba a su reelección, con el estandarte de seguir con el proceso de paz.

La campaña presidencial fue intensa, con ataques constantes al proceso de paz por parte de los opositores, en cabeza de Zuluaga, mientras por su parte del gobierno nacional hacía publicidad a favor del proceso, al utilizar la figura de la selección nacional de fútbol, cuyas figuras daban declaraciones sobre la necesidad y la importancia de que el pueblo colombiano eligiera el camino de la paz; en otras palabras, que se votara por Santos, para que este continuara con los diálogos con la guerrilla de las FARC, con el lema: "Colombianos juguemos todos juntos el partido de la paz". Cabe resaltar que, no obstante, las elecciones estuvieron tan reñidas que diferentes actores y candidatos políticos fueron haciendo alianzas con cada una de las campańas; lo que resultó en una segunda vuelta electoral.

Esa situación episódica, de unidad, resumida en la expresión "el espejismo de un solo pueblo" (Quitián, 2014) tuvo como operador de nacionalidad -en los términos de Alabarces (2002)- a la Selección Colombia. Sin embargo lo que ocurrió en esos meses previos al Mundial y en la propia Copa no fue del todo espontáneo; el gobierno trabajó activamente en promover ciertas escenas y producir ciertos símbolos como el Pabellón Nacional y una emisión filatélica conmemorativa de su participación en el Mundial de Fútbol de Brasil-2014; de hecho, el candidato-presidente, en la conmemoración de este acto, hizo evidente este mensaje: "Después de 16 ańos volvemos a un Campeonato Mundial de Fútbol y volvemos en unas circunstancias muy especiales. Estamos dentro de los cinco mejores equipos del mundo de acuerdo a la Fifa. Y este equipo liderado por el profesor Pekerman es ahora por los próximos 50 días, el máximo simbolo de la unidad nacional' (Santos, mayo de 2014; sin cursivas en el original). Incluso, no dudó en mencionar los diálogos de paz en su alocución, vinculando a la guerrilla, eterno contradictor del establecimiento, en este imaginario de unidad que estaba apuntalando con dicho acto:

La bandera que le acabo de entregar a Mario Alberto Yepes, el capitán del equipo es exactamente eso. Le estoy entregando la bandera de nuestra Patria, para que este equipo nos represente como lo sabe hacer: con determinación, con coraje, con espíritu deportivo y con ganas de triunfo allá en Brasil.

Esa unidad nacional que ustedes representan es muy importante en estos momentos para el país.

Cuando los estemos viendo [jugar] los partidos todas las diferencias en el país van a desaparecer, porque detrás de ustedes van a estar los 47 millones de colombianos.

No importa a qué partido político pertenezcan, no importa a qué religión pertenezcan, no importa cuáles sean las diferencias. Inclusive aquellas personas con las cuales estamos hoy conversando para terminar el conflicto armado, ellos también los estarán apoyando (Santos, mayo de 2014).

Y ambos no dudaron en hacerlo: varias veces, a bando y bando se le vio con la camiseta de la Selección; y a la guerrilla ni le importó que uno de los patrocinadores y diseñador de la camiseta oficial fuera "un instrumento del capitalismo", como tantas veces pregonaran en sus discursos en contra de las industrias globalizadas. Tampoco el candidato-presidente vaciló en ningún momento en usar otro referente del deporte; en sus palabras (en aquella misma alocución), afirmó:

[...] Ustedes, como dice el uniforme: 'estamos todos unidos', pero además piensan en grande y pensando en grande es exactamente como hemos llegado a donde hemos llegado en el fútbol y en el deporte.

Hoy Rigoberto Urán está comandando ni más ni menos que el Giro de Italia, que también hay una coincidencia, una coincidencia muy linda. 
Rigoberto Urán es víctima de esta guerra, su padre fue asesinado por esta guerra. Pero él supo superarse y hoy está de campeón, como son ustedes unos campeones, como quiero que sea toda Colombia: una campeona unida, todos unidos, porque así es como progresan las naciones (Santos, mayo de 2014) ${ }^{3}$.

En el entretanto, el candidato-presidente, Juan Manuel Santos, invitaba a ver los encuentros de la selección Colombia en el mundial de fútbol Brasil 2014, en especial aquel contra el seleccionado de Grecia, invitando a todos los colombianos a ponerse la camiseta "por el equipo de la paz"; mensaje latente que tendría su efecto, al utilizar el fútbol como una metáfora de unión (Carrión, 2006), más aún con a partir de la necesidad de continuar con los diálogos con la guerrilla. La suerte, o el desempeño deportivo, ayudó a consolidar este discurso, gracias a que el seleccionado colombiano venció a su similar de Grecia tres goles por cero, lo que generó una gran euforia y, como si fuera poco, en la rueda de prensa varios jugadores invitaron a todos los colombianos a ir con la camiseta puesta a votar por la paz. Aunque no fuera el único factor determinante, efectivamente Juan Manuel Santos es elegido, de nuevo, como el presidente de Colombia por un periodo de cuatro años, gran parte de los cuales habría prometido invertirlos en llegar a buen término con el proceso de paz con las FARC. Así, la historia política del país ha empezado a contar con un actor adicional, pero la pregunta sería ¿̇el fútbol puede ser un hecho sociocultural, que a partir de sus resultados positivos, puede definir desde el apoyo a la paz por parte de sus seguidores gracias a una figura de unidad nacional, hasta incluso definir elecciones?

Afinando más la pregunta: ¿Fue el Mundial un hecho social total (Mauss, 1979, Da Matta, 1982, Archetti, 2003) que futbolizó al país: su economía, su política, su guerra, su cultura durante ese mes en el que el único lenguaje posible era el de la Selección Colombia? ¿Fue el balompié una "institución cero" (Guedes, 1977) que le prestó su estructura al gobierno y a la sociedad para emitir- recibir y retroalimentar el diálogo nacional durante los días del Mundial de Brasil 2014?

No solo sus discursos soldaban a la Selección Colombia con la paz sino, además, asistió a actos que, aunque no eran novedosos (el Distrito Capital era viejo referente de estas iniciativas), servían para apuntalar su mensaje de unidad-deporte-nación. Así, sus palabras en el la clausura del Mundialito de Seguridad y Convivencia Ciudadana, celebrado en Bogotá, seguirían la línea trazada meses atrás:

Decirles que este acto sencillo, discreto, me llena de emoción porque esto es otra forma muy importante de ir construyendo la paz en este país, de ir reconciliando a esta Nación y de ir sembrando un mejor futuro.

Eso es lo que estamos haciendo hoy y por eso interrumpí la campaña para venir a estar con ustedes.

Lo que acabamos de escuchar, del capitán del equipo del Comandos Azules, "usted es de Millonarios y yo soy de Santa Fe, pero nos vamos a dar un abrazo", eso es sembrar paz.

[...]

De manera que muchas gracias generales, muchas gracias a la Policía y muchas gracias a todos ustedes, muchas gracias a los equipos.

Por eso esta es una forma integral de ver la seguridad y la convivencia ciudadana.

Integrar a la Policía con las comunidades y a las comunidades con la Policía ha sido siempre un objetivo de mi Gobierno y esta es una demostración más de que sí se puede y se puede en torno a causas tan nobles, tan importantes como las que hoy estamos presenciando.

3 Palabras del Presidente Juan Manuel Santos en la entrega del Pabellón Nacional a la Selección Colombia y el lanzamiento de la emisión filatélica conmemorativa del Mundial de Fútbol Brasil 2014; Bogotá, 23 de mayo" (http://wsp.presidencia.gov.co/ Prensa/2014/Mayo/Paginas/20140523_02-Palabras-del-Presidente-Santos-entrega-Pabellon-Nacional-Seleccion-Colombiaemision-filatelica-Mundial-Futbol-B.aspx). 


\section{$[\ldots]$}

Me voy de aquí realmente emocionado. Me voy de aquí lleno de entusiasmo para seguir buscando esa paz, para seguir sembrando esa paz, sin bajar la guardia en materia de seguridad, como debe ser la obligación de nuestra Policía (Santos, Junio de 2014) ${ }^{4}$.

No transcurrió ni un mes, cuando, esta vez con motivo de la Selección Colombia frente a Japón, reiteró el mensaje de unidad:

Quiero a nombre de los 47 millones de colombianos mandarle un saludo muy, muy especial, una felicitación muy especial a toda la Selección.

$[\ldots]$

Ustedes saben que el deporte, el fútbol, rompe barreras, mueve montañas y esto está moviendo el optimismo de los colombianos.

Estamos haciendo un papel realmente muy positivo allá en Brasil y esto nos enorgullece a todos (Santos, junio de 2014) .

Su estrategia discursiva no escatimó en el uso inclusivo de la primera persona gramatical del plural; ese "nosotros" que involucra a todos los actores y que es la semilla del discurso de la unidad; recordaba, incluso, aquel comercial que promocionaba su reelección y su bandera por la paz, donde le preguntaba a una señora del público si "prestaría sus hijos para la guerra"; ahora él era quien tomaba hijos prestados para "consolidar ese sentimiento de deseo de paz". Ese relato incluyente también sería usado en el discurso de felicitaciones por el triunfo contra Uruguay:

Colombia está feliz, todos estamos felices. Hoy es un día histórico. Nuestra Selección pasó a cuartos de final, la primera vez en la historia que Colombia llega a ese punto. Y vamos a continuar.

Tengo que, primero que todo, felicitar a nuestra Selección [...].

Toda Colombia está apoyando a nuestra Selección, toda Colombia se siente orgullosa de nuestra Selección, porque nuestra Selección nos está mostrando un camino: que cuando se piensa en grande y se actúa en grande, se logran los objetivos. Y eso es lo que esta Selección nos está diciendo a todos los colombianos ${ }^{6}$.

En la pérdida ante Brasil no dejó de utilizar esta herramienta discursiva, pues sabía que, aunque derrotados, los discursos de unidad difundidos por los medios y la propaganda habían dejado servido para apuntalar ese "sentimiento de unidad"; así, ese nosotros sería, una vez más, su eslogan:

Periodista: Un mensaje para la Selección Colombia.

Presidente Santos: Pues acabo de hablar con ellos, les dije que toda Colombia se siente muy, muy orgullosa de nuestra Selección. Nos hicieron muy felices, llegaron muy lejos, nunca habíamos llegado tan lejos.

4 Palabras del Presidente Juan Manuel Santos durante la Clausura del Mundialito de Seguridad y Convivencia Ciudadana; Bogotá, 10 junio (http://wsp.presidencia.gov.co/Prensa/2014/Junio/Paginas/20140610_02-Palabras-Presidente-Juan-Manuel-Santos-durantela-Clausura-del-Mundialito-de-Seguridad-y-Convivencia-Ciudadana.aspx).

5 Declaración del Presidente Juan Manuel Santos tras el triunfo de Colombia por 4-1 en el partido contra Japón en el Mundial Brasil 2014; Bogotá, 24 de junio (http://wsp.presidencia.gov.co/Prensa/2014/Junio/Paginas/20140624_03-Palabras-Presidente-Santostras-el-triunfo-Colombia-por-4-1-partido-Japon-Mundial-Brasil-2014.aspx).

6 Declaración del Presidente Juan Manuel Santos luego del triunfo de la Selección Colombiana de Fútbol ante la de Uruguay en el Mundial Brasil 2014, Cartagena, 28 de junio (http://wsp.presidencia.gov.co/Prensa/2014/Junio/Paginas/20140628_02-PalabrasDeclaracion-Presidente-Juan-Manuel-Santos-triunfo-Seleccion-Colombiana-Futbol-Uruguay-Mundial-Brasil.aspx). 
Hicieron un gran espectáculo para el mundo entero, el mundo entero está admirando a Colombia gracias a la Selección.

A veces se gana, a veces se pierde, este partido además lo hemos debido ganar porque Colombia jugó mejor que Brasil.

$[\ldots]$

Periodista: Presidente, tenemos equipo para rato, ¿̨no?

Presidente Santos: Pues sí, es que son jóvenes, todos son jóvenes, no se nos olvide que llegamos a este partido con el goleador del Campeonato Mundial, con James (Rodríguez), que hoy además metió otro gol, llegamos como el equipo con menos goles en contra, segundo con más goles a favor y sobre todo, con la admiración del mundo entero y eso es un triunfo ya de por sí (Santos, julio de 2014; sin cursivas en el original $)^{7}$.

Más aún, luego de las elecciones y de su triunfo presidencial reelectoral, siguió aprovechándose de la figura de la Selección Colombia para reiterar el camino que quería seguir en sus próximo cuatrienio de mando:

Queridos compatriotas:

Esta es mi primera alocución al país desde las pasadas elecciones y quiero -antes que nada- expresar mi gratitud a los colombianos que ratificaron mi mandato para buscar la paz con prosperidad social.

A eso dedicaré los próximos cuatro años de gobierno, e invito desde ahora a los que acompañaron nuestras propuestas - pero también a los que votaron por otras opciones o no votaron- a que se unan a la construcción de una paz justa, una paz con verdad, una paz con reconciliación... una paz con unidad.

TODO, todo lo podemos lograr si trabajamos - como la Selección Colombia- ¡UNIDOS POR UN PAÍS!

Esa es la gran lección que nos dejaron estos colombianos admirables, estos grandes deportistas y grandes seres humanos que nos representaron en el Mundial de Fútbol.

Lo que vimos ayer en el estadio de Fortaleza no fue una selección achicada ni con miedo, sino una selección con ganas de triunfo, con capacidad; combativa y talentosa.

Nos ganó el pentacampeón del mundo en su propio país y por la mínima diferencia.

Pero nadie puede negar que ha sido Colombia la que puso la alegría y el buen fútbol en el Mundial de Brasil.

¡Qué hazaña la de nuestros muchachos!

¡Llegaron más lejos que nunca antes en toda nuestra historia deportiva!

No solo clasificamos entre las 8 mejores selecciones del mundo, sino que se hizo una campaña formidable: 4 partidos ganados de 5 jugados; 12 goles a favor y solo 4 en contra, y -hasta el momento- tenemos el mayor goleador del Mundial, que es nuestro querido y admirado James Rodríguez.

¡MUCHAS GRACIAS! ¡Muchas gracias a nuestros jugadores que lo dejaron todo en la cancha, con honor, con dignidad y con juego limpio!

¡Muchas gracias al profesor Pekerman y a su excelente equipo de asistentes técnicos, que nos recordaron cómo juega Colombia y la importancia de sońar!

¡Muchas gracias a la Federación Colombiana de Fútbol!

7 Declaración del Presidente Juan Manuel Santos al término del encuentro entre Colombia y Brasil (Fortaleza, Brasil), 4 de julio (http://wsp.presidencia.gov.co/Prensa/2014/Julio/Paginas/20140704_04-Palabras-del-Presidente-Santos-al-termino-del-encuentroentre-Colombia-Brasil.aspx) 
Vienen nuevos retos... El año entrante se juega la Copa América en Chile, y no solo podemos, sino que ¡vamos a ser campeones!, como ya lo fuimos en el 2001.

Porque tenemos una selección joven y -además- tendremos a Falcao.

Y vendrá el Mundial de Rusia en el 2018, donde Colombia -con toda seguridad-será protagonista, porque aprendimos a ganar $\mathrm{i} y$ no vamos a dejar que se nos olvide!

Las eliminatorias para este mundial comenzarán el próximo año.

Por eso creo que interpreto a la inmensa mayoría de los colombianos cuando le pido a la Federación que ojalá ratifique al profesor Pekerman como técnico, para que continúe este proceso que ha sabido llevar con éxito, altura y profesionalismo.

Porque la Selección nos unió como país y nos mostró lo mejor de los colombianos: ese talento, esa capacidad de lucha, esa determinación que vimos ayer - por ejemplo- en ese segundo tiempo al que solo le faltaron unos minutos para la gloria

¡Qué compromiso el de nuestros jugadores!

¡Así es Colombia! Así vamos a ganar este otro gran partido que estamos jugando: ¡el de la paz con prosperidad social!

Y no es solo la Selección la que nos da ejemplo:

Caterine Ibargüen ganó otra vez esta semana en Europa. nuestros ciclistas hicieron el 1-2 y la montaña en el Giro de Italia; hace 8 días nuestros automovilistas hicieron el 1-2-3 en la primera carrera de la IndyCar, tenemos a tres tenistas entre los 100 mejores del mundo.

Nuestros deportistas nos enseñan, más que nadie, de qué estamos hechos los colombianos. Ellos nos demuestran hasta dónde podemos llegar si trabajamos UNIDOS, si trabajamos con disciplina y entusiasmo por las buenas causas.

¡Qué orgullo! ¡Qué orgullo nuestra Selección Colombia!

¡Qué orgullo ser colombianos!

Recibámoslos como se merecen y digámosles:

\section{¡GRACIAS! ¡MUCHAS GRACIAS POR LA ALEGRÍA Y POR ENSEÑARNOS A SOÑAR!}

Buenas noches (Santos, julio de 2014; sin negrillas) ${ }^{8}$

Entre tanto, en La Habana, en una misma mesa, no solo se estaban negociando posiciones tan importantes, como el conflicto agrario, la exclusión política o la injusticia social, sino que también están sentados a la mesa aquellos que se declararan enemigos irreconciliables; quienes, además, disfrutaron a la par los partidos del seleccionado colombiano contra, Grecia, Costa de Marfil, Japón, Uruguay y Brasil; además, cuando cada uno de los integrantes de la mesa de negociación debía dar declaraciones en público, en esa época tanto guerrilleros como representantes del gobierno colombiano salían a rueda de prensa portando la camiseta de la selección Colombia; incluso, durante el mundial se produjeron más 1.500 comunicados por redes sociales (Twitter y Facebook), por parte de los dos grupos que integran la mesa de negociación.

8 Alocución del Presidente Juan Manuel Santos de agradecimiento a la Selección Colombia de Fútbol; Bogotá, 5 de julio (http://wsp. presidencia.gov.co/Prensa/2014/Julio/Paginas/20140705_04-Palabras-Alocucion-Presidente-Santos-agradecimiento-la-SeleccionColombia-Futbol.aspx). 


\section{Epílogo}

Nos encantaría poder preguntarle al director de la película colombiana Golpe de estadio si alguna vez imaginó que lo que él plantearía pudiera pasar: la política y la guerra en clave de fútbol, o los asuntos nacionales mediados por el discurso de las sociedades futbolizadas; pero lo que sí es claro es que en Colombia la realidad supera la ficción y, como diría Gracia Márquez, "Colombia es Macondo".

\section{Referencias}

Alabarces, P. (2002). Fútbol y patria. El fútbol y las narrativas de la nación argentina. Prometeo libros, Buenos Aires.

Archetti, E. (2003) Masculinidades. Fútbol, Polo y Tango en Argentina. Buenos Aires: Antropofagia.

Carrión, F. (2006). Biblioteca del fútbol ecuatoriano (cinco tomos). Quito: FLACSO.

Da Matta, R. (1982) Universo do futebol: esporte e sociedade brasileira. Ediçôes Pinakotheke, Rio de Janeiro.

Guedes, S. (1977) O futebol brasileiro: instituição zero. Rio de Janeiro: Programa de Pós- Graduação em antropologia social, Museu Nacional.

Mauss, M. (1979). Sociología y antropología. Editorial Tecnos, Madrid.

Quitián, D. "Las elecciones, el espejismo de un solo pueblo y la Copa Mundo: apuntes desde Brasil sobre las campañas del gobierno Santos y de la Selección Colombia", en Cuadernos del mundial Brasil 2014, CLACSO. No. 5. Julio de 2014, Versión disponible: http://cuadernosdelmundial.clacso.org/opinion17.php 